\title{
Epidemiology of Brucellosis in Saudi Arabia
}

Malak Al Anazi, HSQM, Isamme AlFayyad, MA, Rawan AlOtaibi, HSQM, Amani Abu-Shaheen, MPH.

\begin{abstract}
الأهداف : تقديم ملخص شامل للإصابة بداء البروسيلات

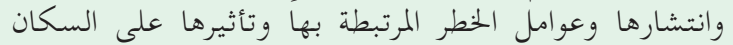
السعوديين.

المنهجية: أجريت مراجعة منهجية باستخدام قاعدة بيانات PubMed

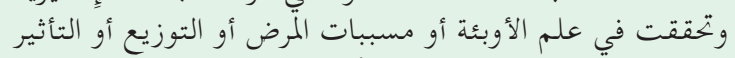

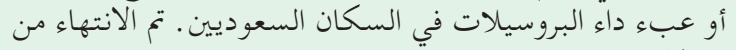

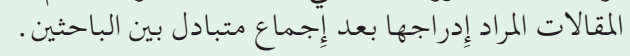

النتائج: اشتملت الدراسة على سبعة عشر (n=17) دراسة فئسة

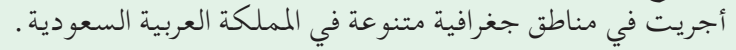

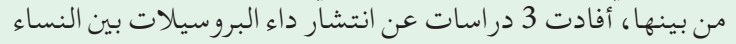

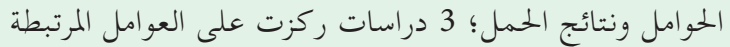

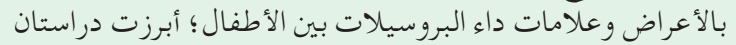

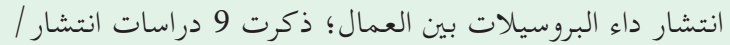

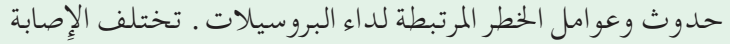

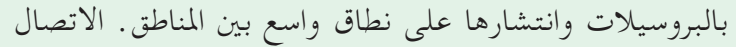

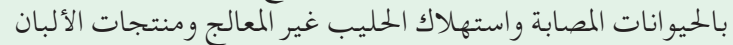

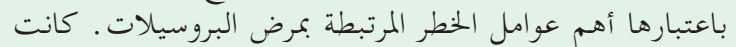

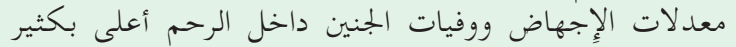

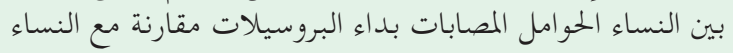
الحوامل دون داء البروسيلات المصابات بداء.

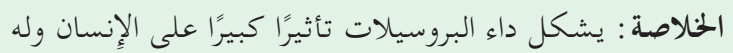

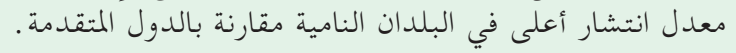

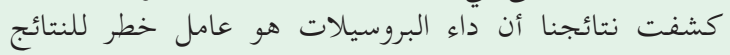

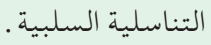

Objectives: To provide a comprehensive summary of brucellosis incidence, prevalence, risk associated factors, and impact on the Saudi population.

Methods: A systematic review was conducted using the PubMed database. The articles included in the review were written in English and investigated the epidemiology, etiology, distribution, impact, or burden of brucellosis in the Saudi population. Articles to be included were finalized after a mutual consensus of 2 researchers.
Results: Seventeen ( $\mathrm{n}=17)$ studies were included which were conducted in diverse geographical areas of Saudi Arabia. Of them, 3 studies reported the prevalence of brucellosis among pregnant women and pregnancy outcomes; 3 studies focused on risk associated factors and symptoms and signs of brucellosis among children; 2 studies highlighted the prevalence of brucellosis among workers; 9 studies reported the prevalence/incidence and risk associated factors of brucellosis. Brucellosis incidence and prevalence vary widely among regions. Contact with infected animals and consumption of raw milk and milk products were identified as the main risk associated factors of brucellosis. Abortion and intrauterine fetal deaths rates were significantly higher among pregnant women with brucellosis compared with pregnant women without brucellosis.

Conclusion: Brucellosis poses a considerable impact on human and has a higher prevalence in developing countries as compared to developed countries. Our results revealed that brucellosis is a risk factor for adverse reproductive outcomes.

PROSPERO No: CRD4201912430

Saudi Med J 2019; Vol. 40 (10): 981-988 doi: 10.15537/smj.2019.10.24027

From the Quality Department (AlAnazi), from the Research Center (AlFayyad, Abu-Shaheen), King Fahad Medical City, and from the Nursing Department (AlOtaibi), King Faisal Specialist Hospital and Research Center, Riyadh, Kingdom of Saudi Arabia.

Received 18th March 2019. Accepted 15th July 2019.

Address correspondence and reprint request to: Dr. Amani Abu-Shaheen, Research Center, King Fahad Medical City, Riyadh, Kingdom of Saudi Arabia. E-mail: aabushaheen@kfmc.med.sa ORCID ID: https://orcid.org/0000-0002-1019-5548 
B rucellosis is one of the common bacterial zoonotic infections worldwide, and it poses a major threat to human and animal health. ${ }^{1}$ Brucella spp. is responsible for causing brucellosis. Due to its contagious nature and impact on human health, it is considered as a biological agent. ${ }^{2}$ In Sub-Saharan Africa, brucellosis infects over 500,000 humans annually. ${ }^{3}$ However, lack of reporting and misdiagnosis with other diseases is responsible for its inaccurate incidence. ${ }^{3}$ Moreover, the socio-demographic profile of the population and the strength of the country's brucellosis eradication program leads to diversity in brucellosis incidence.

An epidemiological study conducted in Uganda also highlighted that the prevalence and incidence of brucellosis are not clearly understood. ${ }^{4}$ Though the disease is prevalent all over the globe, the major regions for the public health concern are the Mediterranean region, the Middle East, Africa, and Latin America., ${ }^{3,5}$

Human brucellosis is life-threatening and its clinical presentation includes non-specific symptoms such as intermittent fever, weight loss, depression, hepatomegaly, splenomegaly joint pain. ${ }^{6}$ Also, brucellosis leads to financial burden due to loss of normal daily activities ${ }^{7}$ and there is a loss of animal production as well. ${ }^{8}$ An animal disease evaluation in Kenya listed brucellosis as one of the top 10 factors that affect the lives of the poor.'

Transmission of brucellosis in humans is either by direct or indirect contact with infected animals or with the consumption of contaminated foods. ${ }^{10}$ Unpasteurized dairy products from infected animals are considered as a source of public infection in developing countries as limited infrastructure for disease control was available. ${ }^{11}$ For meat packaging industry workers, contaminated carcasses are the major source of infection. ${ }^{11}$ According to veterinarians, contamination while supporting births in infected livestock and unintentional vaccine exposure are also responsible for obtaining brucellosis. ${ }^{12}$

Also, the transmission is being remarkably affected by the contact with infected products of aborted animals, ${ }^{12}$ in addition clinical laboratories and abattoirs have reported airborne transmission of bacteria to humans. ${ }^{13}$ Due to the traditional practice of consuming raw milk primarily from sheep and camel in Saudi Arabia, the main causative factors are unpasteurized

Disclosure. Authors have no conflict of interests, and the work was not supported or funded by any drug company. raw milk consumption and contact with the infected animals. ${ }^{14-16}$

One of the most frequently reported diseases in Saudi Arabia is human brucellosis, especially in Riyadh city. ${ }^{13-15,17-20}$ Numerous studies have been conducted on brucellosis in different regions of Saudi Arabia. ${ }^{13-15,20-23}$ However, the threat of brucellosis to humans has expanded as no systematic review has been conducted to assess the epidemiology of brucellosis in Saudi Arabia. To evaluate the extent of the disease and to identify the current knowledge on brucellosis in the Saudi population, this review aims to provide a comprehensive overview of brucellosis incidence, prevalence, risk associated factors, and its effects. To avoid future brucellosis epidemics, this review also identifies areas where research is sorely required.

Methods. Relevant papers published until March 2016 were searched online using PubMed. The following keywords were used in the search approach: "brucellosis," "Brucella," "epidemiology," "prevalence," "incidence," "risk," “impact," and "Saudi Arabia". All the relevant articles, except interventional studies and case reports/series which focused on brucellosis's epidemiology, etiology, distribution, impact or burden on Saudi people and were written in English were included in the review.

After conducting the online search, 51 articles were identified. The post-abstract screening were classified into 2 segments: i) relevant articles (which focused on human brucellosis infection); and ii) irrelevant articles (which were related to non-human brucellosis or which were out of scope of the current review, such as articles on brucellosis genetic behavior, the laboratory diagnostic tests associated with the screening of human brucellosis, as well as the experimental studies on animal models). The articles were further analyzed by screening their full text versions. This involved 2 reviewers who assessed each article and confirmed if they were relevant or irrelevant for the study. In case of classification related discrepancies, discussion was conducted for resolution.

Furthermore, the relevant articles were classified as following frequency studies: a) Prevalence studies which included definite study population: setting and outcome. For example, to identify study population as seropositive for brucellosis. b) Incidence studies which indicated the time period of observation: included study population size, setting, and outcome. For example, the number of new brucellosis cases per population at risk per time period.

Articles to be included in the study were finalized after the mutual consensus of 2 reviewers. Newcastle 
Ottawa scale for case-control and cohort study was used to assess the quality as well as the risk of bias of the included studies.

Results. After the mutual consensus of the researchers, 17 articles met the inclusion criteria with publication dates ranging between 1984 and 2011 (Figure 1). According to Newcastle Ottawa scale, most of the studies included scored from medium to lower bias. The studies included were conducted in a variety of geographical areas in Saudi Arabia. Of the 17 articles, 3 studies reported the prevalence of brucellosis among pregnant women and pregnancy outcomes. Likewise, 3 studies reported the risk associated factors and symptoms and signs of brucellosis among children. Moreover, 2 studies reported the prevalence of brucellosis among workers, while 9 studies reported the prevalence/incidence and risk associated factors of brucellosis (Table 1).

Prevalencelincidence, risk associated factors, signs, and symptoms of brucellosis. Aloufi et $\mathrm{al}^{21}$ described the trend of human brucellosis disease in Saudi Arabia between 2004 and 2012 in 37,477 reported cases during this period. The study reported a significant decrease in the incidence risk from 22.9 in 2004 to 12.5 in 2012. Fallatah et $a^{22}$ conducted a study on 159 brucellosis patients and $>1: 160$ Brucella titer patients. Fever was observed in 126 (79.2\%) patients; joint pain in 112 (70.4\%); and bone pain in 77 (48.4\%) patients. In addition, abdominal pain in 18 patients $(11.3 \%)$, vomiting in $9(5.7 \%)$, anorexia in $6(3.8 \%)$; splenomegaly in $6(3.8 \%)$, hepatomegaly and lymphadenopathy in 2 (1.3\%) patients were also observed. In 1984, Talukder et $\mathrm{al}^{23}$ reported an estimated prevalence of brucellosis at the Armed Forces Hospital, Riyadh, Kingdom of Saudi Arabia of 1733 patients, of this 153 (8.8\%) cases were positive. Another study conducted in 1997 by Elbeltagy ${ }^{24}$ in Tabuk province, Saudi Arabia of 137 cases estimated brucellosis prevalence as 34 in 100,000 people with the mean (SD) age of 33.8 (13.9) years and male:female ratio of $1.8: 1$. There were $63.5 \%$ cases residing in rural areas, $58.4 \%$ retained livestock at home, 27\% worked on farms and with livestock and $88.3 \%$ reported ingestion of raw milk in past. Brucella melitensis was the most common infecting agent followed by Brucella abortus, and Brucella suis. Cases of splenomegaly in $25.5 \%$ and hepatomegaly in $22.6 \%$ were reported. ${ }^{24}$ Likewise, Malik ${ }^{10}$ assessed 104 Saudi patients and reported the most common symptoms as fever in $100 \%$, sweating in $96.2 \%$, headache in $76.9 \%$, joint pain in $76.9 \%$, and backache in $73.1 \%$ cases. Fever $(96.2 \%)$, splenomegaly $(42.3 \%)$, hepatomegaly (46.2\%), spine tenderness (30.8\%), arthritis (26.9\%) and lymphadenopathy $(19.2 \%)$ were the some of the physical findings.

Symptoms including mild anemia, leukopenia, and relative lymphocytosis commonly observed among the study participants. A significant factor in disease transmission was ingestion of raw milk (84.6\%), followed by occupational contact with animals in $73 \%$, and raw liver consumption in $63.3 \% .^{10}$

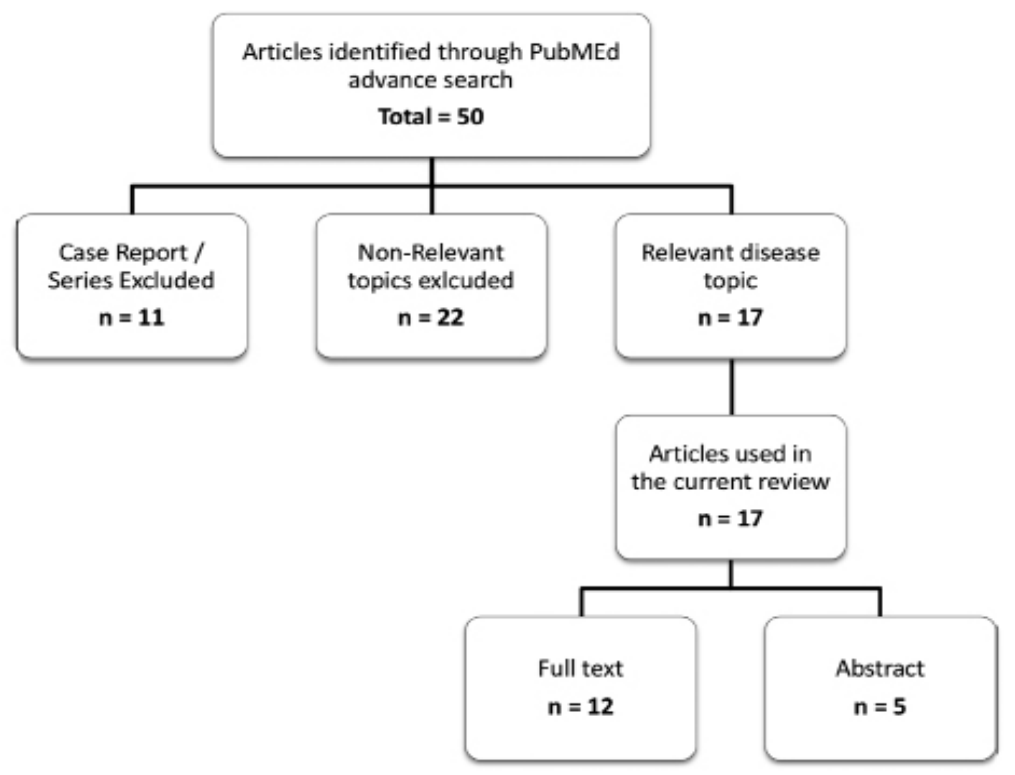

Figure 1 - Flow chart of the literature review search. 
Table 1 - The summary of studies involved in the systematic review.

\begin{tabular}{|c|c|c|c|c|c|}
\hline Study & Sample size & Study setting & $\begin{array}{c}\text { Year of data } \\
\text { collection }\end{array}$ & $\begin{array}{c}\text { Prevalence/ } \\
\text { incidence }\end{array}$ & Other findings \\
\hline \multicolumn{6}{|c|}{ Prevalence/incidence, risk associated factors, signs, and symptoms of brucellosis } \\
\hline Talukder et al, ${ }^{23} 1984$ & 1733 patient & Hospital & 1984 & $8.8 \%$ & $\begin{array}{l}\text { The result of } 1733 \text { patients sera tested revealed that } 153(8.8 \%) \text { were } \\
\text { positive. }\end{array}$ \\
\hline Cooper, ${ }^{27} 1991$ & $\begin{array}{l}300 \text { individuals } 150 \text { cases with } \\
\text { brucellosis } \\
150 \text { controls }\end{array}$ & Hospital & 1988 & - & $\begin{array}{l}\text { Notable increase in brucellosis with increasing age and a higher } \\
\text { incidence amongst women than men in some age groups. } \\
\text { There was a seasonal variation in the occurrence of brucellosis. }\end{array}$ \\
\hline Sadat et al, ${ }^{28} 1991$ & $\begin{array}{l}173 \text { patients with a backache } \\
\text { and a history of ingestion of } \\
\text { raw milk }\end{array}$ & Hospital & 1990 & $12.1 \%$ & $\begin{array}{l}\text { Twenty-one patients are suffering from Brucella spondylitis. } \\
\text { Out of } 21 \text { patients, } 14(67 \%) \text { presented with acute signs and symptoms } \\
\text { of B. spondylitis. }\end{array}$ \\
\hline Cooper, ${ }^{26} 1992$ & $\begin{array}{l}300 \text { individuals } 150 \text { cases with } \\
\text { brucellosis } \\
150 \text { controls }\end{array}$ & Hospital & 1988 & & $\begin{array}{l}\text { There was a statistically significant effect of direct contact after allowing } \\
\text { for indirect contact }(\mathrm{OR}=1.77, p<0.05) \text {. } \\
\text { When food types were examined, a significant effect was noted for } \\
\text { buttermilk }(\mathrm{OR}=3.06, p<0.05) \text { and a significant and greater effect were } \\
\text { noted for milk }(\mathrm{OR}=3.82, p<0.00 \mathrm{l}) \text {. }\end{array}$ \\
\hline Albula, ${ }^{25} 1995$ & 4794 subjects & Household & - & $2.3 \%$ & $\begin{array}{l}\text { Direct contact with infected animals and consumption of raw milk and } \\
\text { milk products were identified as the main risk associated factors }\end{array}$ \\
\hline Malik, ${ }^{10} 1997$ & 104 cases of brucellosis & Hospital & $1986-1989$ & - & $\begin{array}{l}\text { Raw milk ingestion was an important factor in disease transmission } \\
(84.6 \%) \text {, followed by close animal contact }(73 \%) \text { and raw liver } \\
\text { consumption }(63.3 \%) \text {. }\end{array}$ \\
\hline Elbeltagy, ${ }^{24} 2001$ & 137 cases of brucellosis & Hospital & 1997 & $34 / 100000$ & $\begin{array}{l}\text { There were } 63.5 \% \text { of cases residue in a rural area, approximately } 58 \% \\
\text { kept animals at home, } 27 \% \text { worked with animals or farms. Moreover, } \\
\text { a history of raw milk ingestion was reported } 88.3 \% \text { of the study } \\
\text { participants. } \\
\text { The most common infecting agents were Brucella melitensis, Brucella } \\
\text { abortus, and Brucella suis. }\end{array}$ \\
\hline Fallatah et al,,$^{22} 2005$ & 159 cases of brucellosis & & $1995-2001$ & - & $\begin{array}{l}\text { One hundred and } 59 \text { patients had a diagnostic label of brucellosis and a } \\
\text { brucella titer of }>1: 160 \text {. } \\
\text { They recorded abdominal pain in } 18 \text { patients }(11.3 \%) \text { vomiting } \\
\text { in } 9(5.7 \%) \text { and anorexia in } 6(3.8 \%) \text {; splenomegaly in } 6(3.8 \%) \text {, } \\
\text { hepatomegaly and lymphadenopathy in } 2(1.3 \%) \text { patients. }\end{array}$ \\
\hline Aloufi et al, ${ }^{21} 2016$ & 37,477 cases & $\begin{array}{l}\text { Saudi } \\
\text { National } \\
\text { Registry }\end{array}$ & $2004-2012$ & $22.9-12.5$ & $\begin{array}{l}\text { The IRs significantly decreased from } 22.9 \text { in } 2004[95 \% \text { confidence } \\
\text { interval }(\mathrm{CI})=22.3,23.5] \text { to } 12.5 \text { in } 2012(95 \% \mathrm{CI}=12.1,13) \text {. } \\
\text { Young, male Saudi citizens living in highly endemic areas were at } \\
\text { greatest risk of acquiring brucellosis. }\end{array}$ \\
\hline \multicolumn{6}{|c|}{ The incidence of brucellosis among pregnant women and pregnancy outcomes } \\
\hline Sharif et al, ${ }^{31} 1990$ & 537 pregnant women & Hospital & - & - & $\begin{array}{l}\text { Of the } 513 \text { women who were tested, } 18(3.5 \%) \text { have a positive titer. } \\
\text { Of } 24 \text { patients in whom the test was carried out because of symptoms } \\
\text { suggestive of brucellosis, all were positive. }\end{array}$ \\
\hline Khan et al, ${ }^{30} 2001$ & $\begin{array}{l}92 \text { pregnant women } \\
\text { with acute brucellosis }\end{array}$ & Hospital & $1983-1995$ & $1.3 / 1000$ & $\begin{array}{l}\text { Overall, } 43 \% \text { of pregnant women with acute brucellosis had } \\
\text { spontaneous abortions during the first or second trimester, and } 2 \% \text { had } \\
\text { intrauterine fetal deaths in the third trimester. }\end{array}$ \\
\hline Elshamy et al, ${ }^{29} 2008$ & $\begin{array}{l}\text { Groups: } \\
55 \text { pregnant women positive } \\
\text { for Brucella antibodies } \\
395 \text { matched pregnant } \\
\text { controls }\end{array}$ & $\begin{array}{l}\text { Hospital and } \\
\text { Clinic }\end{array}$ & $2005-2007$ & - & $\begin{array}{l}\text { A statistically significant difference was found in abortion and } \\
\text { intrauterine fetal death rates. } \\
\text { No statistically significant difference was found in the preterm labor } \\
\text { rates between the pregnant women with positive brucellosis antibodies } \\
\text { and control groups. }\end{array}$ \\
\hline \multicolumn{6}{|c|}{ Risk associated factors, signs, and symptoms of brucellosis among children } \\
\hline Al-Eissa et al, ${ }^{19} 1990$ & 102 children with brucellosis & Hospital & 1990 & - & $\begin{array}{l}\text { The most source of infection was the consumption of raw milk ( } 80 \%) \\
\text { patients. } \\
\text { The common symptoms were fever, arthralgia, malaise, weight loss, } \\
\text { arthritis, hepatosplenomegaly, and lymphadenopathy. }\end{array}$ \\
\hline Benjamin et al, ${ }^{33} 1992$ & 157 children with brucellosis & Hospital & 1991 & - & $\begin{array}{l}\text { Approximately } 22 \% \text { gave a history of animal contact or ingesting raw } \\
\text { milk, milk products, or raw liver. } \\
\text { Three-quarters of the patients had an acute or subacute presentation } \\
\text { with diverse symptomatology }\end{array}$ \\
\hline AlShaalan et al, ${ }^{34} 2002$ & 115 with brucellosis & Hospital & $1984-1995$ & - & $\begin{array}{l}\text { Consumption of unpasteurized milk mainly camel was the primary } \\
\text { source of infection. } \\
\text { The clinical picture was dominated by arthritis } 70 \% \text {. }\end{array}$ \\
\hline \multicolumn{6}{|c|}{ Prevalence of brucellosis among workers } \\
\hline AlSekait, ${ }^{32} 1993$ & 1200 abattoir workers & Abattoir & 1991 & $4.0 \%$ & $\begin{array}{l}\text { Brucellosis was common among butchers, veterinarians }(8.9 \%) \text {, and } \\
\text { veterinary assistants }(5.4 \%) \text {, and administrative personnel }(1.1 \%) \text {. }\end{array}$ \\
\hline Elsheikh et al, ${ }^{35} 2011$ & $\begin{array}{l}2 \text { Groups: } \\
540 \text { healthy people } \\
900 \text { patients }\end{array}$ & $\begin{array}{l}\text { Farms and } \\
\text { abattoir } \\
\text { Hospital }\end{array}$ & $2009-2010$ & $(7.3 \%)$ & $\begin{array}{l}\text { The results of ELISA revealed that all healthy people samples were } \\
\text { negative for IgM antibodies, while } 12 \text { were positive for IgG antibodies. } \\
\text { Thirty of the feverish patient's samples were positive for IgM } \\
\text { antibodies, while } 66 \text { were positive for IgG antibodies. }\end{array}$ \\
\hline
\end{tabular}


A house-to-house survey was conducted to assess the nationwide prevalence of brucellosis and randomly collected 4900 subjects. The study reported serological evidence of exposure to Brucella antigen in $19.2 \%$ of southern region population and active disease in 2.3\% population. Major risk factors associated were direct contact with infected animals and consumption of raw milk and milk products. ${ }^{25}$ Similarly, Cooper ${ }^{26}$ reported consumption of unpasteurized dairy products as the main risk factor associated with brucellosis. When considering products from particular animal, intake of milk and Zaban (buttermilk) had higher risks than cheese or uncooked liver.

Cooper ${ }^{27}$ reported brucellosis to be more common among Saudi residents than immigrants. The study also reported a substantial rise in brucellosis with increasing age. Females of some age groups were more affected as compared to males. Moreover, the study revealed an impact of season on brucellosis as its occurrence was more commonly observed in spring and summer seasons. ${ }^{27}$ Sadat et $\mathrm{al}^{28}$ prospectively screened patients $(\mathrm{n}=173)$ with backache complaint and history of raw milk ingestion and reported 21 patients infected with Brucella spondylitis. Among 21 patients, 14 had severe signs and symptoms of $B$. spondylitis and 6 patients were hospitalized. A positive titer of $B$. melitensis and $B$. abortus were present in most patients. ${ }^{28}$

The incidence of brucellosis among pregnant women and pregnancy outcomes. A prospective study on 450 pregnant women, conducted between August 2005 and December 2007, reported that incidence of brucellosis $12.2 \%$ among the study participant. Among them, the incidence of abortion was reported in $27.27 \%$ cases while the incidence of intrauterine fetal deaths was observed in $12.72 \%$ and preterm labor in $10.90 \%$ cases. Comparing women with a positive and negative titer, abortion and intrauterine fetal deaths rates had statistically significant difference while preterm labor rates had no significant difference. ${ }^{29}$ Khan et $\mathrm{al}^{30}$ reported that the incidence of pregnancy and brucellosis was 1.3 cases/1000 delivered obstetrical discharges between 1983 and 1995 . The rate of incidence of abortion in the first and second trimesters was $43 \%$, and the rate of intrauterine fetal deaths in the third trimester was $2 \%{ }^{30}$ A study conducted by Sharif et $\mathrm{al}^{31}$ showed that among 513 women who were tested routinely, positive titer was found in 3.5\% $(\mathrm{n}=18)$ patients. Among 24 patients in whom the test was performed as symptoms indicative of brucellosis, $100 \%$ were positive. Abortion incidence among pregnant women with Brucella titres $<1: 160$ was $7.7 \%$ and in $>1: 160$ was $17.6 \%(p>0.05){ }^{31}$
Risk associated factors, signs and symptoms of brucellosis among children. AlShaalan et $\mathrm{a}^{32}$ conducted a study on children to investigate signs and symptoms and the risk factors associated with brucellosis. Among the study participants, the intake of unpasteurized milk (camel) was the primary source of brucellosis. The majority (70\%) of cases presented had arthritis, followed by $20 \%$ non-specific febrile illness without localizing signs and $10 \%$ febrile illness with rare presentations. Bacteremia was observed in $45 \%$ and in B. melitensis was observed in $96 \%$ cases. Benjamin et al ${ }^{33}$ studied prospectively 157 brucellosis infected children at Abha, Saudi Arabia. History of animal contact or raw milk and milk products ingestion, or raw liver were found in approximately $92 \%$. Acute or subacute presentation with diverse symptomatology was found in $75 \%$ of patients: fever in $100 \%$, malaise in $91 \%$, anorexia in $68 \%$, cough in $20 \%$, abdominal symptoms in $20 \%$, and arthralgia in $25 \%$. Some of the other common findings were hepatomegaly $(31 \%)$, splenomegaly $(55 \%)$, and lymphadenopathy (18\%). Seven out of 16 (44\%) patients were infected with $B$. melitensis. ${ }^{33} \mathrm{Al}$-Eissa et al ${ }^{19}$ also reported raw milk ingestion to be the main source of infection in $80 \%$ of the patients. Fever, arthralgia, malaise, weight loss, arthritis, hepatosplenomegaly, and lymphadenopathy were the main signs and symptoms presented. B. melitensis was isolated from $75 \%$ of the patients.

Prevalence of brucellosis among workers. AlSekait ${ }^{34}$ documented an overall prevalence of brucellosis among abattoir workers to be $4 \%$. Infection was prevalent among $8.9 \%$ butchers, $5.4 \%$ veterinarians and veterinary assistants and $1.1 \%$ administrative personnel. Elsheikh et $\mathrm{al}^{35}$ followed up the latest situation in the Najran region in terms of the prevalence of brucellosis in humans and animals. The results revealed the prevalence of brucellosis infection in diseased humans as $7.3 \%$ and in animals as $15 \%$.

Discussion. The current review is providing a comprehensive summary of brucellosis incidence, prevalence, risk associated factors, and impact on the Saudi population. One of the main factors that affected the quality of the identified studies in this review was the lack of clarity in describing the methods used, mainly on how they define the cases and the sampling technique. For some studies, we were not able to assess whether the study had been designed to control the bias.

Varied incidence and prevalence of brucellosis exist between countries and in the country itself. Study bias might be the potential cause of these differences. However, they cannot be excluded or removed. A study 
conducted in the Southern region of Saudi Arabia on 4900 subjects reported active disease in $2.3 \%$ and serological evidence of exposure to Brucella antigen in $19.2 \% .{ }^{25}$ However, a study in Riyadh on 1733 patients estimated the prevalence of brucellosis to be 8.8\% (153 patients had positive brucellosis). ${ }^{23}$ Time and region of the study might be the 2 differentiating factors. Seroprevalence rates in developing countries from the Middle East also vary from $8 \%$ in Jordan ${ }^{36}$ and $5 \%$ in Lebanon to $12 \%$ in Kuwait. ${ }^{37,38}$ Low and middle-income countries had a higher prevalence than in developed countries. However, specific sub-groups of these populations such as Turkish immigrants in Germany are targets of brucellosis. ${ }^{20}$ In the United States, human brucellosis is uncommon. Prevalence is less than 0.5 cases per 100,000 persons and for the last 10 years, approximately 100 cases have been reported annually. ${ }^{39}$ In China, prevalence of human brucellosis increased from 0.92 cases $/ 100,000$ people to 2.62 cases/100,000 people from 2004 to $2010 .{ }^{40}$ National statistics from the Saudi Arabian Ministry of Health has reported that brucellosis prevalence in 1990 was the highest with 72 cases/100,000 persons annually and had been consistent since 1996 with 32 and 38 cases $/ 100,000$ persons per year. ${ }^{41}$

Moreover, our review revealed that brucellosis prevalence rate among pregnant women ranges from $0.13 \%$ ( 1.3 cases $/ 1000$ delivered obstetrical discharges) to $12.2 \% .{ }^{29-31}$ AlSekait $^{34}$ reported a $4 \%$ prevalence of brucellosis in abattoir workers, while, in the Najran region, the prevalence was $7.3 \%$ among farms and abattoir workers. ${ }^{35}$ There has been an improvement in the identification of cases in 2011, which might be due to one or combination of the following: data accuracy, appropriate diagnosis (using better screening tools) or increased awareness of brucellosis among health care providers. Seroprevalence of brucellosis among abattoir workers was $37.6 \%$ in Algeria ${ }^{42}$ and $4.1 \%$ in Brazil. ${ }^{43}$ Direct contact with infected animals and raw milk and milk products intake were the main risk factors associated with brucellosis. ${ }^{10,24-26}$ Likewise, the main source of infection in children was the consumption of unpasteurized milk ${ }^{19,32,33}$ as reported from a prospective study conducted on 157 brucellosis children at Abha, Saudi Arabia. A majority (92\%) demonstrated history of contact with animals and consumption of raw milk and milk products. In addition, many other countries reported similar factors. ${ }^{44-46}$ However, many studies also reported other robust risk factors such as fresh cheese and unpasteurized milk products. ${ }^{47-49}$

Our review documented the most common presenting symptoms of brucellosis in Saudi patients to be fever, hepatomegaly, splenomegaly, tendered spine, arthritis, and lymphadenopathy. Mild anemia, leukopenia, and relative lymphocytosis were common as well. ${ }^{10,22,24}$ B. melitensis, B. abortus, ${ }^{28}$ and $B$. suis were the most common infecting agents. ${ }^{24}$ Likewise, our review showed the most frequently encountered brucellosis symptoms among children as fever, arthralgia, malaise, weight loss, arthritis, hepatosplenomegaly, and lymphadenopathy and also the isolation of B. melitensis species from most patients. ${ }^{19,32,33}$ It has been reported in the literature that almost every organ can be affected, and varied complications may occur. ${ }^{50,51}$

In comparison to other bacterial infections, brucellosis causes more abortion, preterm labor, and intrauterine fetal deaths as reported by Hartigan. ${ }^{52}$ Pregnant women with brucellosis have more chances of abortion and intrauterine fetal deaths than pregnant women without brucellosis. ${ }^{29}$ In pregnant women with brucellosis, spontaneous abortion incidence was $43 \%$ in first and second trimesters, and intrauterine fetal deaths rate was $2 \%$ in the third trimester; ${ }^{30,53,54}$ however, the study by Seoud et al ${ }^{55}$ contradicts and reports Brucella infection to play an insignificant role in abortion.

In order to decrease the incidence of brucellosis at the national level, substantial educational programs for healthcare workers, veterinary practitioners and cattle owners should be started in the high-risk areas covering the major risk factors associated with brucellosis as well as economic and zoonotic importance. Regular surveillance should be carried out to identify the status of this control and prevention programs.

This review limits our search for English-language papers. However, the majority of the studies conducted in the Arab world by research institutes and universities are in English. As we searched only PubMed, we might have missed some articles. In Saudi Arabia, of the major cross-sectional studies, few were observed for the prognosis, burden, and consequences of brucellosis on the society and healthcare services. Also, the findings of the included studies were not modified for test performance as they may show diversity as per the laboratory protocol and this information was not available.

In conclusion, the contribute to brucellosis disease incidence/prevalence varied within regions. Brucellosis has a huge impact on human and has higher prevalence in developed countries. Also, the results presented brucellosis as a risk factor for adverse reproductive outcomes. The studies conducted in Saudi Arabia identified contact with diseased animals and raw milk and milk products ingestion as the main risk factors associated with brucellosis. Identified risk factors associated with brucellosis are modifiable and 
by focusing on public awareness programs, such issues can be eradicated. High-quality studies and healthcare services are required to explore the prognosis and burden of these diseases on the Saudi society and this should be emphasized for future study.

\section{References}

1. Seleem MN, Boyle SM, Sriranganathan N. Brucellosis: a re-emerging zoonosis. Vet Microbiol 2010; 140: 392-398.

2. Godfroid J, Cloeckaert A, Liautard JP, Kohler S, Fretin D, Walravens K, et al. From the discovery of the Malta fever's agent to the discovery of a marine mammal reservoir, brucellosis has continuously been a re-emerging zoonosis. Vet Res 2005; 36 : 313-326.

3. McDermott JJ, Arimi SM. Brucellosis in sub-Saharan Africa: epidemiology, control and impact. Vet Microbiol 2002; 90 : 111-134.

4. Bernard F, Vincent C, Matthieu L, David R, James D. Tuberculosis and brucellosis prevalence survey on dairy cattle in Mbarara milk basin (Uganda). Prev Vet Med 2005; 67: 267-281.

5. Lopez MA. Brucellosis in Latin America. In: Young EJ, Corbel $\mathrm{MH}$, editors. Brucellosis: clinical and laboratory aspects. Boca Raton (FL): CRC Press Inc; 1989. p. 151-161.

6. Bingöl A, Yücemen N, Meço O. Medically treated intraspinal "Brucella" granuloma. Surg Neurol 199; 52: 570-576.

7. Corbel M. Brucellosis in humans and animals. World Health Organization, Food and Agriculture Organization of the United Nations, World Organization for Animal Health. [Updated 2006, Accessed 2016 March 7]. Available from: http://www. who.int/csr/resources/publications/Brucellosis.pdf

8. Roth F, Zinsstag J, Orkhon D, Chimed-Ochir G, Hutton G, Cosivi O, et al. Human health benefits from livestock vaccination for brucellosis: case study. Bull World Health Organ 2003; 81: 867-876.

9. Perry BD. Animal disease impact on the poor: study results, investing in animal health research to alleviate poverty. International Livestock Research Institute 2002: 67-77.

10. Malik GM. A clinical study of brucellosis in adults in the Asir region of southern Saudi Arabia. Am J Trop Med Hyg 1997; 56: 375-377.

11. Fernandez-Prada CM, Zelazowska EB, Nikolich M, Hadfield Tl, Roop II RM, Robertson GL, et al. Interactions between Brucella melitensis and human phagocytes: bacterial surface O-Polysaccharide inhibits phagocytosis, bacterial killing, and subsequent host cell apoptosis. Infect Immun 2003; 71: 2110-2119.

12. Billard E, Cazevieille C, Dornand J, Gross A. High susceptibility of human dendritic cells to invasion by the intracellular pathogens Brucella suis, B. abortus, and B. melitensis. Infect Immun 2005; 73: 8418-8424.

13. Memish Z, Mah M, Khan MY, Aalmahmoud S, Alshaalan M. Brucellosis: clinical and laboratory observations in 160 bacteremic patients. J Infect 2000; 4: 59-63.

14. Hafez SM. The impact of uncontrolled animal importation and marketing on the prevalence of brucellosis in Saudi Arabia. Ann Saudi Med 1986; 6: S15-S18.

15. Alshaalan MA, Memish ZA, Almahmoud SA, Alomari A, Khan MY, Almuneef M, et al. Brucellosis in children: clinical observations in 115 children. Int J Infect Dis 2002; 6: 182-186.
16. Pappas G, Papadimitriou P, Akritidis N, Christou L, Tsianos EV. The new global map of human brucellosis. Lancet Infect Dis 2006; 6: 91-99.

17. Khan MY. Brucellosis: observations on 100 patients. Ann Saudi Med 1986; 6: 19-23.

18. Kiel F, Khan MY. Analysis of 506 consecutive positive serologic tests for brucellosis in Saudi Arabia. J Clinical Microbiol 1987; 25: 1384-1387.

19. Al-Eissa YA, Kambal AM, al-Nasser MN, al-Habib SA, al-Fawaz IM, al-Zamil FA. Childhood brucellosis: a study of 102 cases. Pediatr Infect Dis J 1990; 9: 74-79.

20. Almuneef M, Memish Z, Alshaalan M, Albanyan E, Alaloola S, Balkhy HH. Brucella melitensis bacteremia in children: review of 62 cases. J Chemother 2003; 15: 76-80.

21. Aloufia AD, Memish ZA, Assiri AM, McNabbb SJ. Trends of reported human cases of brucellosis, Kingdom of Saudi Arabia, 2004-2012. J Epidemiol Glob Health 2016; 6: 11-18.

22. Fallatah SM, Oduloju AJ, Al-Dusari SN, Fakunle YM. Human brucellosis in Northern Saudi Arabia. Saudi Med J 2005; 26 : 1562-1562.

23. Talukder MA, Moaz A, Al Admawy O, Higham RH, Legaspi E. Brucellosis: experiences in Saudi Arabia. Dev Biol Stand 1984; 56: 597-599.

24. Elbeltagy KE. An epidemiological profile of brucellosis in Tabuk Province, Saudi Arabia. East Mediterr Health J 2001; 7 : 791-798.

25. Alballa SR. Epidemiology of human brucellosis in southern Saudi Arabia. J Trop Med Hyg 1995; 98: 185-189.

26. Cooper CW. Risk factors in transmission of brucellosis from animals to humans in Saudi Arabia. Trans R Soc Trop Med Hyg 1992; 86: 206-209.

27. Cooper CW. The epidemiology of human brucellosis in a welldefined urban population in Saudi Arabia. J Trop Med Hyg 1991; 94: 416-422.

28. Sadat-Ali M, al-Mousa MS, al-Salem AH. Brucellosis as a cause of backache. Trop Geogr Med 1991; 43: 148-151.

29. Elshamy M, Ahmed AI. The effects of maternal brucellosis on pregnancy outcome. J Infect Dev Ctries 2008; 2: 230-234.

30. Khan MY, Mah MW, Memish ZA. Brucellosis in pregnant women. Clin Infect Dis 2001; 32: 1172-1177.

31. Sharif A, Reyes Z, Thomassen P. Screening for brucellosis in pregnant women. J Trop Med Hyg 1990; 93: 42-43.

32. Shaalan MA, Memish ZA, Mahmoud SA, Alomari A, Khan MY, Almuneef $\mathrm{M}$, et al. Brucellosis in children: clinical observations in 115 cases. Int J Infect Dis 2002; 6: 182-186.

33. Benjamin B, Annobil SH. Childhood brucellosis in southwestern Saudi Arabia: a 5-year experience. J Trop Pediatr 1992; 38: 167-172.

34. AlSekait MA. Prevalence of brucellosis among abattoir workers in Saudi Arabia. J R Soc Health 1993; 113: 230-233.

35. Elsheikh AA, Masoud EE, Mostafa MF, Elkhawanky MM. Seroprevalence of 2 zoonotic diseases in Southwestern Saudi Arabia. Rift Valley fever and brucellosis. Saudi Med J 2011; 32: 740-741.

36. Dajani YF, Masoud AA, Barakat HF. Epidemiology and diagnosis of human brucellosis in Jordan. J Trop Med Hyg 1989; 92: 209-214.

37. Araj GF, Azzam RA. Seroprevalence of brucella antibodies among persons in high-risk occupation in Lebanon. Epidemiol Infect 1996; 117: 281-288.

38. Lulu AR, Araj GF, Khateeb MI, Mustafa MY, Yusuf AR, Fenech FF. Human brucellosis in Kuwait: a prospective study of 400 cases. QJ Med 1988; 66: 39-54. 
39. Centers for Disease Control and Prevention (CDC). Brucellosis 2016. [Updated 2019]. Available from: https://www.cdc.gov/ brucellosis/index.html

40. Li Y, Yu X, He T. An analysis of brucellosis epidemic situation in humans from 2004 to 2010 in China. Chin J Control Endemic Diseases 2012; 27: 18-20.

41. Memish Z. Brucellosis control in Saudi Arabia: prospects and challenges. J Chemother 2001; 13: S11-S17.

42. Habib A, Near A, Qamor J, Azrot R. Prevalence of brucellosis: a serological study in Tiaret, Western Algeria. Arab Gulf J Scientific Res 2003; 21: 244-248.

43. Ramos TR, Pinheiro Junior JW, Moura Sobrinho PA, Santana VL, Guerra NR, de Melo LE, et al. Epidemiological aspects of an infection by Brucella abortus in risk occupational groups in the microregion of Araguaina, Tocantins. Braz J Infect Dis 2008; 12: 133-138.

44. Hartigan P. Human brucellosis: epidemiology and clinical manifestations. Irish Veterinary Journal 1997; 50: 179-180.

45. Issa H, Jamal M. Brucellosis in children in south Jordan. East Med Health J 1999; 5: 895-902.

46. Corbell JM. Brucellosis: epidemiology and prevalence worldwide. In: Young EJ, Corbell JM, eds. Brucellosis: clinical and laboratory aspects. Boca Raton (FL): CRC Press; 1989: 26-37.

47. Gwida M, Al DS, Melzer F, Rosler U, Neubauer H, Tomaso H. Brucellosis - regionally emerging zoonotic disease? Croat Med J 2010; 51: 289-295.
48. Bikas C, Jelastopulu E, Leotsinidis M, Kondakis X. Epidemiology of human brucellosis in a rural area of northwestern Peloponnese in Greece. Eur J Epidemiol 2003; 18 : 267-274.

49. Cetinkaya Z, Aktepe OC, Ciftci IH, Demirel R. Seroprevalence of human brucellosis in a rural area of Western Anatolia, Turkey. J Health Popul Nutr 2005; 23: 137-141.

50. Jubber AS, Gunawardana DR, Lulu AR. Acute pulmonary edema in brucella myocarditis and interstitial pneumonitis. Chest 1990; 97: 1008-1009.

51. Akdeniz H, Irmak H, Anlar O, Demiröz AP. Central nervous system brucellosis: presentation, diagnosis and treatment. $J$ Infect 1998; 36: 297-301.

52. Hackmon R, Bar-David J, Bashiri A, Mazor M. Brucellosis in pregnancy. Harefuah 1998; 135: 3-7, 88.

53. Malone FD, Athanassiou A, Nores LA, Dalton ME. Poor perinatal outcome associated with maternal Brucella abortus infection. Obstet Gynecol 1997; 90: 674-676.

54. Makhseed M, Harouny A, Araj G, Moussa MA, Sharma P. Obstetric and gynecologic implication of brucellosis in Kuwait. J Perinatol 1998; 18: 196-199.

55. Seoud M, Saade G, Awar G, Uwaydah M. Brucellosis in pregnancy. J Reprods Med 19914; 36: 441-445. 